\title{
MULHERES LÍDERES: AS DESIGUALDADES DE GÊNERO, CARREIRA E FAMÍLIA NAS ORGANIZAÇÕES DE TRABALHO.
}

\section{WOMEN LEADERS: THE GENDER INEQUALITY, CAREER AND FAMILY IN WORK ORGANIZATIONS.}

\author{
Julice Salvagni \\ Doutoranda pela Universidade Federal do Rio Grande do Sul, UFRGS, Brasil \\ Professora pela Instituição Educacional São Judas Tadeu, IESJT_PPROV, Brasil \\ E-mail: julicesalvagni@gmail.com
}

\section{Janaina Canabarro}

Graduada pela Faculdade Integrada de Santa Maria - FISMA, Brasil Professora pela Faculdade Integrada de Santa Maria - FISMA, Brasil E-mail: jcanabarro@gmail.com 


\title{
MULHERES LÍDERES: AS DESIGUALDADES DE GÊNERO, CARREIRA E FAMÍLIA NAS ORGANIZAÇÕES DE TRABALHO.
}

\section{RESUMO}

Este estudo tem como objetivo mostrar o caminho percorrido pelas mulheres líderes na organização onde trabalham, investigando as dificuldades e desafios enfrentados por elas para a concretização dos projetos pessoais e profissionais. Para o embasamento teórico foram definidos os tópicos: Diversidade na liderança, que aborda o emprego dos atributos de ambos os gêneros na gestão das empresas e carreira, trabalho e família, que apresenta as novas configurações familiares e as transformações econômicas e sociais ocorridas no âmbito do trabalho. Para a coleta dos dados foram realizadas entrevistas individuais com seis gestoras. A análise dos diálogos se deu por meio de quatro categorias: planejamento de carreira; trabalho e família; estilo de liderança e características da liderança de gênero do ponto de vista do líder homem. Finalmente, os dados apontaram que a construção e o sucesso na carreira implicam muito estudo, esforço e autodesenvolvimento. Elas vivem o conflito do equilíbrio do pessoal com o profissional e preocupam-se em desempenhar bem as várias figuras - mulher, mãe, esposa e gestora. Apresentam características de sensibilidade, flexibilidade e parceria no trabalho em equipe, sendo exigentes e objetivas quando a situação obriga. Verifica-se a necessidade de maior observação nos estilos de liderança, associados à dicotomia dos perfis de comportamento masculino e feminino de gerenciar.

Palavras-chave: Desigualdade de gênero. Carreira. Liderança. Diversidade na liderança.

\section{WOMEN LEADERS: THE GENDER INEQUALITY, CAREER AND FAMILY IN WORK ORGANIZATIONS.}

\begin{abstract}
This study aims to show the path taken by women leaders in the organization where they work, investigating the difficulties and challenges faced by them in order to achieve personal and professional projects. The chosen topics for the theoretical basis are: Diversity in leadership, which addresses the use of attributes of both genders in business management and Career, work and family, which features new family configurations and the economic and social changes in the workplace. To collect the data, six managers were interviewed individually. The analysis of the dialogues was performed through four categories: Career Planning; Work and family; Leadership style and gender characteristics of leadership from the point of view of a man leader. Finally, the data showed that in order to build and have a successful career, lots of study, effort and selfdevelopment are required. They live the conflict of knowing how to balance personal and professional life and they worry about performing well in several figures - woman, mother, wife and manager. They show characteristics of sensitivity, flexibility and partnership in team work, being strict and objective when the situation demands. There is a need for further observation in leadership styles, connected with a dichotomy of male and female behavior profiles when managing.
\end{abstract}

Keywords: Career. Leadership. Diversity in leadership. Gender Inequalities.

Revista de Gestão e Secretariado - GeSec, São Paulo, v.6, n. 2, p 88-110, maio./agosto. 2015. 


\section{INTRODUÇÃO}

Durante muitos anos, coube à mulher apenas o papel referente à esfera do privado, no que diz respeito a cuidar dos filhos, do marido e de todas as tarefas domésticas. Aspectos de produção de bens, ou mesmo das decisões centrais à ordem pública, são marcadas historicamente como sendo de competência ao universo masculino, atribuindo ao homem, em igual medida, a pertença de uma suposta representação da força, da virilidade e da segurança social.

Com a industrialização, a partir do século XIX (Kanan, 2010; Fontenele-Mourão, 2006), as mulheres passaram a questionar a soberania do masculino e, paulatinamente, vêm lutando contra o medo enraizado na autoridade estabelecida das relações de gênero. Assim, começaram a refletir sobre sua identidade social e sua submissão ao homem e adentraram no mundo corporativo, até então predominantemente masculino, e, portanto, em dimensões do domínio público. Passaram a ter direito ao voto, controlar o número de filhos, conquistaram a liberdade de desfazer um vínculo matrimonial, ascenderam nos espaços de formação profissional e passaram a gozar de certa liberdade sexual, o que, entre outros fatores, contribui para uma significativa mudança atual acerca do anteriormente concebido "sexo frágil".

Vistas como "as rainhas do lar", marcadas por atividades domésticas em grande parte não reconhecidas, as mulheres não tinham os afazeres domésticos contabilizados como atividade econômica nos levantamentos censitários e domiciliares do Instituto Brasileiro de Geografia e Estatística (IBGE), entre as décadas de 1970 e 1980. As pessoas que declaravam exercer essas funções eram inseridas nos dados da População Economicamente Inativa - PEI. No decorrer das pesquisas, entendeu-se que essas atividades, que consomem tempo e energia de quem as realiza, são consideradas como trabalho não remunerado, e não como inatividade. (Bruschini, 2007)

Ao longo dos anos, o estereótipo feminino sofreu grande transformação e as mulheres começaram a ocupar o mercado de trabalho e tiveram de provar que são tão capazes e competentes quanto os homens para assumir posições importantes dentro da organização. Nesse sentido, estão se destacando cada vez mais inclusive em cargos que, historicamente, são considerados masculinizados como a advocacia, engenharia, procuradoria e magistratura.

A participação feminina no mercado de trabalho tem aumentado de forma linear e praticamente alheia às flutuações da atividade econômica. Seja em fases de recessão, seja nos ciclos de expansão da economia, a taxa de atividade das mulheres, em particular das cônjuges com filhos, tem crescido no Brasil nos últimos 20 anos. A absorção de mão de

Revista de Gestão e Secretariado - GeSec, São Paulo, v.6, n. 2, p 88-110, maio./agosto. 2015. 
obra feminina tem sido superior à masculina em todas as fases recentes da economia brasileira. (Lavinas, 2001 apud Fontenele-Mourão, 2006, p. 17).

A crescente participação das mulheres no mercado de trabalho e a constante luta pela conquista de seus direitos, quebrando paradigmas, buscando reconhecimento e igualdade, estudando mais, desenvolvendo habilidades e atitudes, estando mais atentas ao ambiente dos negócios, exigindo respeito quanto ao seu reconhecimento como cidadã, ainda não são suficientes para combater a desigualdade de gênero nas relações de trabalho. Este fato se reflete, entre outros, no gap entre os salários masculinos e femininos e nos cargos estratégicos e de liderança dentro das empresas.

Embora a desigualdade de gênero, em que o masculino é o dominante, ainda persista, presume-se que intuição, comunicação, organização, visão sistêmica, entre outros diversos atributos, fazem a diferença no ato de liderar pessoas e são qualidades valorizadas na hora de se caracterizar a liderança feminina. Mesmo não considerando essas características como inatas, mas sim características socialmente construídas atribuídas à mulher, estas podem ser vistas pelas empresas como uma forma de se obter vantagem competitiva.

Essa mudança no cenário globalizado faz lançar a seguinte questão de pesquisa: quais os desafios enfrentados por mulheres em cargos de liderança na sobreposição da vida profissional/pessoal do ponto de vista das desigualdades de gênero? Visto que a mulher, além da carga horária a cumprir dentro da empresa, não raro permanece como principal responsável pelos cuidados com os filhos e com os afazeres domésticos, assumindo uma tripla jornada de trabalho (trabalhadora, mãe e esposa), supõe-se que há uma sobrecarga de trabalho ainda desmedida que intensifica tanto os percursos das conquistas profissionais femininas, como a consolidação de uma carreira de gestão nas empresas. Diante dessa perspectiva, é interessante saber quais elementos influenciam para o atingimento dos objetivos e expectativas pessoais.

Nesse sentido, o presente estudo tem como objetivo analisar a trajetória das mulheres que galgaram melhores posições e que hoje são gestoras influentes nas organizações em que trabalham, sendo importante, como objetivos específicos, compreender as dificuldades enfrentadas para equilibrar vida pessoal e profissional e identificar os fatores que atuam no desenvolvimento da carreira e ao alcance de objetivos pessoais e metas profissionais, ambos serão descritos nesta pesquisa por meio de relatos das entrevistas.

Este trabalho se faz necessário dadas as notáveis desigualdades de gênero no mercado de trabalho que, somadas à atribuição socialmente construída da mulher como mantenedora do lar, torna a trajetória de trabalho díspar. Conforme as mulheres foram se inserindo e ascendendo no Revista de Gestão e Secretariado - GeSec, São Paulo, v.6, n. 2, p 88-110, maio./agosto. 2015. 
mercado de trabalho suas relações sociais mudaram. Elas passaram a ocupar os dois espaços: o doméstico e o laboral, como donas de casa e trabalhadoras. Entretanto, a desigualdade de gênero ainda persiste no que se refere à divisão do trabalho doméstico. No indicador de horas semanais empregadas nas atividades domésticas de homens e mulheres revelou que a jornada deles era de 10 horas e as mulheres ficavam envolvidas na função em média 20,8 horas, além de sua jornada de trabalho (IBGE, 2013, p. 151), fator que muitas vezes limita o seu desenvolvimento e desempenho profissional, o que não acontece, via de regra, com os homens.

O texto apresenta aspectos da diversidade de gênero em relação à liderança, especialmente sob a premissa das desigualdades entre homens e mulheres no mercado de trabalho. Além disso, elencam-se a essas questões a dinâmica familiar que se faz sob um acúmulo de tarefas atribuídas à figura feminina, o que acarreta maior sobrecarga de trabalho à mulher e, portanto, interfere diretamente na sua carreira profissional.

\section{REVISÃO DE LITERATURA}

\subsection{DIVERSIDADE NA LIDERANÇA}

Entende-se por gênero a diferença socialmente construída entre homens e mulheres. O termo, muitas vezes, é confundido com sexo, o qual se refere ao masculino e feminino, dado físicobiológico - o conceito de gênero vai muito além. Gênero é a identidade social também formada pelas atribuições de diferenças de comportamento e qualidades de homens e mulheres. Kanan (2010, p. 245) explica que "[...] homens e mulheres se constroem a partir de práticas e relações que instituem vários aspectos como gestos, modo de ser e estar no mundo, formas de falar, maneira de agir, condutas e posturas apropriadas e distintas".

Essa é uma das formas de se conceitualizar gênero, tendo em vista que há divergências sobre o seu entendimento. Porém, esta será refutada ao longo deste trabalho, em que os comportamentos e qualidades de cada gênero serão utilizados simultaneamente, tanto para homens, como para mulheres, sem conceber que há uma postura apropriada a cada identidade.

O que se busca mostrar é que indiferente do gênero, ou do sexo, todos possuem características individuais que podem trazer benefícios tanto para a organização, quanto às equipes de trabalho. Ou seja, estas marcas identitárias das diferenças de gênero são alegações usadas pelo mercado de trabalho como justificativa pela não ascensão das mulheres, colocando a mulher como 
eterna parte constituinte de uma esfera inferiorizada, como também acontece com os negros, índios, dentre outros.

Nicholson (2000) propõe algumas definições de conceitos centrais à temática e percorre a historicidade desses termos a fim de, ao final do texto, lançar algumas perspectivas epistemológicas às questões de gênero, mesmo que pouco desenvolvidas na ocasião. A autora estabelece uma primeira definição acerca do conceito de gênero que é "tipicamente pensado como referência à personalidade e comportamento, não ao corpo; "gênero" e "sexo"; são portanto compreendidos como distintos" (p. 2). De qualquer forma, completa que "se o próprio corpo é sempre visto através de uma interpretação social, então o 'sexo' não pode ser independente do 'gênero'; antes, sexo nesse sentido deve ser algo que possa ser subsumido pelo gênero" (p. 2). Com isso, o gênero é visto, numa perspectiva ampla, enquanto "a organização social da diferença sexual [...], embora não possa ser isolado de sua implicação num amplo espectro de contextos discursivos” (p. 2). Isso nos sugere que a construção do gênero independe do sexo, embora a identificação biológica pareça ainda ser um indicador importante, mesmo que se leve em consideração a apropriação socialmente construída desta correlação.

Sobre o caráter de construção social do gênero, Piscitelli (2008) destaca a importância de "ferramentas analíticas para apreender a articulação de múltiplas diferenças e desigualdades” (p. 266). Dentre elas, a autora destaca as leituras sistêmicas: nas quais a noção de interação entre formas de subordinação possibilitaria superar a noção de superposição de opressões; e as abordagens construcionistas: que apresentam aspectos dinâmicos e relacionais da identidade social e são marcantes a visão de poder em termos de lutas contínuas em torno da hegemonia.

Transformações demográficas, culturais e sociais que ocorreram no Brasil, afetaram, portanto, essas mulheres e suas famílias. Uma delas foi a diminuição da fecundidade reduzindo o número de filhos, liberando-as para o trabalho, principalmente em regiões mais desenvolvidas do País. Outro aspecto importante se refere ao nível de instrução elevado das mulheres em relação aos homens, e o ingresso nas universidades, que possibilitaram o acesso delas às novas oportunidades de trabalho, até em cargos de maior notoriedade dentro das organizações (Bruschini, 2000).

A cada dia, as mulheres têm conseguido mostrar um pouco mais suas habilidades e aptidões no sentido de liderar equipes e gerenciar negócios, devendo, entretanto, ser capazes de desviarem-se dos preconceitos das sociedades. Para Menda (2004, p. 57):

[...] a posição que as mulheres ocupam no mundo do trabalho estrutura os interesses e muitos dos comportamentos cotidianos. Isso nos leva a pensar no trabalho das mulheres e o lugar que ocupam nesse mundo, pois uma situação de igualdade entre homens e mulheres

Revista de Gestão e Secretariado - GeSec, São Paulo, v.6, n. 2, p 88-110, maio./agosto. 2015. 
necessariamente terá que passar também pelo caminho do trabalho das mulheres em pé de igualdade com os homens.

Fontenele-Mourão (2006) relata que o preconceito dos homens em relação às mulheres, no ambiente de trabalho, ato que geralmente desvaloriza a mulher como trabalhadora, ainda é forte, pois eles projetam uma imagem de mulher basicamente ligada à família e a casa - o que limitaria a sua adequada inserção e desempenho na profissão. A autora afirma, ainda, que as relações de gênero vêm passando ao longo do tempo por mudanças em que as mulheres estão se tornando mais independentes e autônomas, modificando suas relações com o trabalho, com a família e com a sexualidade. Assim sendo, no campo profissional, estão ocorrendo modificações nas posições hierárquicas das mulheres dentro das empresas, bem como as competências profissionais e habilidades necessárias ao seu crescimento e desenvolvimento, fato que vai ao encontro do que relatou Bruschini (2000) em seus estudos.

Assim, muito se fala sobre os esforços, atitudes e competências essenciais que a mulher e futura líder deve ter durante sua trajetória dentro da organização para que exista uma harmonia entre a vida pessoal e profissional, sem que haja uma sobrecarga de uma na outra. De acordo com Silva (2000):

[...] as boas práticas contemporâneas de gestão organizacional recomendam confiança, abertura, diálogo, tolerância a erros e incentivo ao espírito empreendedor. O modelo gerencial da nova era exige que se mudem os antigos, já superados e tipicamente masculinos conceitos de competição e agressão pelos de cooperação e relações de afetos, essenciais ao processo de humanização. (Silva, 2000. p. 173).

Nesse ambiente, o tema liderança ganha destaque, onde as qualidades e características dos líderes são relevantes à administração de empresas. Para exercer a atividade de dirigir ou coordenar pessoas, não basta ter poder, autoridade e compreender as necessidades da equipe, também é importante tornar-se um líder. As empresas oferecem programas de capacitação aos colaboradores que ocupam funções de comando para poder, de forma efetiva, exercer a liderança. Não obstante, esses profissionais mesmo participando do mesmo treinamento, os desempenhos individuais apresentados podem variar, posteriormente, devido à influência da personalidade no comportamento profissional. Isso se reflete tanto na liderança masculina quanto na feminina, caracterizando os estilos de liderança pessoais e não por gênero.

Para Hunter (2006), liderança é uma habilidade. A pessoa pode aprender a ser um líder por meio da educação e da aplicação, basta combinar a vontade, os mecanismos e as atitudes certas. $\mathrm{O}$ Revista de Gestão e Secretariado - GeSec, São Paulo, v.6, n. 2, p 88-110, maio./agosto. 2015. 
autor afirma que liderança não é sinônimo de gerência, mas de influência. O bom líder faz com que as pessoas o sigam e contribuam com alegria, sejam mais criativas, tornando-se melhores que são capazes de ser, ou seja, liderança é a habilidade de influenciar pessoas para trabalharem entusiasticamente visando atingir objetivos comuns, inspirando confiança por meio da força do caráter. (Hunter, 2006, p. 18.).

De forma similar, Robbins, Decenzo e Wolter (2013) definem que liderança é a capacidade que o indivíduo demonstra quando influencia o outro a agir de certa maneira por meio de direção, encorajamento, sensibilidade, consideração e apoio, ou seja, o líder motiva seus subordinados a enfrentar desafios ou alcançar objetivos traçados, tantos pessoais quanto profissionais, que considerem difíceis de serem atingidos.

Segundo Araújo, Carmo e Matesco (2013), a condição de líder também pode acontecer por acaso, de forma espontânea, quando alguém da equipe age em benefício dos interesses coletivos, que uma vez atingidos, ele volta para suas atividades normais, e essa pessoa pode ser um colega de trabalho que não tem relação direta com a gestão da equipe.

Pesquisas mostram que mulheres comandam de uma forma que se compara a uma rede de conexões, de relacionamento e trocas, utilizando-se de um estilo mais democrático, encorajando seus subordinados a participar e compartilhar ideias. Já o modelo masculino de gestão tem como característica o estilo de liderança autocrático, centrado em tarefas, na qual os que estão no topo ditam as ordens e os que estão abaixo na pirâmide hierárquica, apenas obedecem (Robbins; Decenzo e Wolter, 2013; Silva, 2000).

No ambiente corporativo não existe maneira ou estilo certo de se praticar a liderança. Homens e mulheres podem contribuir de maneira diferente e agregar resultados também diferentes para as organizações. Desse modo, as mulheres podem utilizar-se de atributos masculinos em sua gestão, assim com as características femininas podem ser aplicadas na liderança masculina, criando assim novas atitudes, tanto cultural quanto comportamental do indivíduo dentro da empresa, não se esquecendo de considerar as crenças, os valores e a cultura organizacional, bem como as ações e conduta da equipe a qual se está gerindo.

Por esse ponto de vista entra-se na questão da androginia, que segundo Santos (2013, p. 96), "[...] é a combinação de atributos femininos e masculinos, eliminando a suposição de dualismo de gênero". O autor afirma ainda que liderança andrógina:

[...] pode ser considerada uma proposição adequada para se estabelecer relações integradas de igualdade de condições e oportunidades de ascensão dos indivíduos, principalmente no que tange às mulheres e à distribuição dos postos de comando nas organizações (Santos, 2013, p. 80).

Revista de Gestão e Secretariado - GeSec, São Paulo, v.6, n. 2, p 88-110, maio./agosto. 2015. 
Concomitantemente, Kanan (2010) considera que:

[...] a diversidade de posturas profissionais, tanto de homens quanto de mulheres, deveria ser melhor considerada pelos detentores de poder, uma vez que a conduta humana jamais será única, afinal, superioridade ou sucesso não são prerrogativas de gênero, pois existem características de atuação próprias de cada um, e cada situação exige comportamentos distintos. (Kanan, 2010, p. 252).

Atualmente, observa-se que as empresas estão exigindo mais a potencialização de resultados por meio das pessoas, independente do gênero, e estas estão tendo de ser mais flexíveis no sentido de se moldarem à situação ou às mudanças que estão ocorrendo no mundo empresarial, definindo quais competências são essenciais ao alcance dos objetivos esperados, pois de nada adianta altos investimentos em tecnologia, empresas bem estruturadas, processos de trabalho inovadores, se os indivíduos não estiverem preparados para assumir quaisquer atividades com qualidade e direitos iguais.

\subsection{CARREIRA, TRABALHO E FAMÍLIA}

Até pouco tempo, a mulher era educada para ser exímia dona de casa, mãe e esposa perfeita, situação que a colocava bem dependente da figura masculina. O objetivo maior de uma mulher costumava ser o casamento e a constituição de uma família, já que o marido era o mantenedor em potencial. Embora essa ainda seja uma realidade em alguns lares, as últimas décadas têm sido fundamentais no que se refere às análises que descrevem e explicam as mudanças no perfil da força de trabalho feminino.

Estudos evidenciam que, ao final dos anos de 1970, as trabalhadoras que eram, em sua maioria, jovens, solteiras e sem filhos, passaram a ser mais velhas, casadas e mães, situação em que houve um crescimento na necessidade de contribuir para a renda familiar, em função do aumento do nível de consumo. Concomitantemente, ocorreu a expansão do nível de escolaridade, o ingresso nas universidades e nas escolhas de carreira. Apesar do habitual ser a formação em áreas como educação, saúde e cultura, as mulheres começaram a alcançar postos de decisão e entraram em setores mais prestigiados, e tradicionalmente masculinos, como medicina, advocacia, e até mesmo em engenharia (Bruschini, 2007, 2000; Bruschini; Puppin, 2004).

Segundo Galeazzi (2001):

Revista de Gestão e Secretariado - GeSec, São Paulo, v.6, n. 2, p 88-110, maio./agosto. 2015. 
[...] diversos fatores impulsionaram esse processo: o desejo de desenvolver uma carreira; a necessidade econômica, seja em decorrência da deterioração dos rendimentos reais do trabalho, seja para fazer frente aos novos anseios de consumo - a alteração no padrão de consumo com a presença de novos produtos, expandindo o leque de consumo familiar, impediu as mulheres a trabalharem fora de casa para aumentar a receita doméstica -; e, principalmente, as elevadas taxas de desenvolvimento econômico. (Galeazzi, 2001, p. 61).

De acordo com os dados da Relação Anual de Informações Sociais (RAIS), base de dados do Ministério do Trabalho e Emprego - MTE - que fornece anualmente informações sobre o mercado de trabalho formal brasileiro, no ano de 2012, a participação das mulheres no emprego formal, nos graus de instrução mais elevados, é superior ao dos homens. No ensino superior incompleto elas representam 52\% de ocupação dos postos de trabalho, enquanto os homens correspondem a 48\%. Com o ensino superior concluído, a diferença do percentual de participação entre os sexos aumenta, consideravelmente. Elas perfazem um total de 59\%, enquanto que eles apresentam uma taxa de atividade de $41 \%$.

Tabela 1.- 2012: emprego por gênero

\begin{tabular}{llll}
\hline Grau de Instrução & Masculino & Feminino & Total \\
\hline Médio Incompleto & 2.405 .322 & 1.286 .720 & 3.692 .042 \\
Médio Completo & 11.664 .808 & 9.331 .484 & 20.996 .292 \\
Superior Incompleto & 912.608 & 988.777 & 1.901 .385 \\
Superior Completo & 3.501 .153 & 4.945 .708 & 8.446 .861 \\
\hline Total & 18.483 .891 & 16.552 .689 & 35.036 .580
\end{tabular}

Fonte: RAIS, 2012.

Kanan (2010) acredita que se a mulher está investindo mais em educação, é porque está buscando levar alguma vantagem em relação aos homens, nos critérios seletivos e nas ofertas de trabalho. Dutra (2002, p. 107), explica que “[...] a compreensão do processo de escolhas da carreira por parte de uma pessoa é importante para entender o conjunto de pressões que pesam sobre ela na realização de seu planejamento". Para Hofmeister (2009), os profissionais de hoje precisam estar sempre se reciclando, estudando, mantendo seus conhecimentos atualizados e desenvolvendo outras habilidades, pois os vínculos de trabalho já não duram tanto quanto antes. "A administração de carreira é uma exigência de qualificação, de especialização e de educação contínua por parte do empregado para que ele possa acompanhar as mudanças tecnológicas e de cenários dos novos tempos" (Hofmeister, 2009, p. 12).

Hoje em dia não há mais espaços nas empresas para profissionais despreparados e desqualificados para a função a ser exercida. A pressão e cobrança por parte da empresa são Revista de Gestão e Secretariado - GeSec, São Paulo, v.6, n. 2, p 88-110, maio./agosto. 2015. 
constantes e as pessoas estão tendo que mudar seu comportamento e postura dentro das organizações. Hofmeister (2009) enfatiza que

\begin{abstract}
[...] neste cenário nos deparemos com um mercado competitivo e acirrado, exigente em relação aos seus profissionais através da produtividade, qualidade, melhora contínua, administrando tempo, e também uma mão-de-obra acuada por fortes exigências externas em relação à escolaridade, qualificação e aperfeiçoamento, exigências internas como a satisfação financeira, autoestima e automotivação. (Hofmeister, 2009, p. 11).
\end{abstract}

Por outro lado, há por parte dos indivíduos uma resistência natural ao planejamento de suas carreiras, mas tornando-se preocupados, nesse ponto, em momentos de crise econômica ou de escassez de emprego, fazendo com que busquem ajuda, conselhos, assessoria ou métodos que os auxiliem nesse processo (Dutra, 2002). Por esse motivo, a pessoa deve ter um papel mais proativo na gestão de sua carreira, pois costuma-se pensar que a gestão da carreira é de responsabilidade somente da empresa, algo definido e pronto, mas pelo contrário, em conjunto com a empresa, a pessoa deve manter-se qualificada e fazer da educação um processo contínuo, ato que possibilita o acompanhando das mudanças no mundo empresarial. Contudo, a mulher considerada por suas características pessoais e de aprendizagem como aquém ao modelo de liderança dominante e masculinizado, não encontrará no ambiente organizacional as mesmas oportunidades de crescimento em relação ao homem, como apontam os dados deste estudo, mesmo sendo capacidade para tanto, unicamente por ser mulher.

O termo "carreira" é bastante utilizado e, para alguns autores, trata-se de um caminho ou etapa a ser trilhado por um indivíduo, algo estruturado e planejado no tempo, com várias alternativas, mas repleto de incertezas. (França, 2011; Oliveira, 2009; Hofmeister, 2009; Dutra, 2002). Para a mulher trabalhadora, além do respaldo da empresa em percebê-la como igual, outro desafio é conciliar as tarefas domésticas, a criação dos filhos com uma carreira e desempenho satisfatório dentro da organização.

Desde a década de 1970, a participação das mulheres vem aumentando no mercado de trabalho, elas cruzaram novos horizontes e começaram a competir com o homem em novos postos de trabalho. Contudo, dois indicadores são relevantes na questão da desigualdade de gênero (Kanan, 2010; Fontenele-Mourão, 2006; Bruschini; Puppin, 2004).

O primeiro se refere aos salários percebidos pelas mulheres em relação aos homens, que mesmo possuindo o nível educacional superior, elas ainda ganham menos, não raras as vezes, realizando a mesma atividade que eles na empresa. De acordo com os dados da Pesquisa Nacional 
por Amostra de Domicílios (PNAD) (IBGE, 2012), o rendimento médio mensal de trabalho dos homens foi de $\mathrm{R} \$ 1.698,00$ e das mulheres de $\mathrm{R} \$ 1.238,00$. Um projeto de lei complementar aprovado pelo Senado em 2012 pode colaborar para equilibrar essa disparidade. O PLC 130/2011 anuncia a aplicação de multa às empresas que não praticarem a igualdade salarial entre homens e mulheres que exercem a mesma função. A medida está nas mãos da presidenta Dilma Rousseff para aprovação. Outra ação importante nesse quesito é o Programa Pró-equidade de Gênero, iniciativa do Governo Federal, que, por meio da Secretaria de Políticas para as Mulheres da Presidência da República (SPM/PR) visa promover a igualdade de oportunidades e de tratamento entre homens e mulheres nas empresas públicas e privadas, especialmente do ponto de vista da isonomia salarial.

O segundo indicador refere-se à ocupação das mulheres em funções mais qualificadas e de maior prestígio na estrutura organizacional, sendo que elas ainda são sub-representadas nas empresas. Na pesquisa realizada pelo IBGE (2013), verificou-se que o acesso de mulheres com 25 anos ou mais de idade aos cargos de direção e gerenciais é menor em comparação ao dos homens nessa faixa etária: 5\% para mulheres e 6,4\% para os homens. Os indivíduos geralmente anseiam por oportunidades de crescimento quando adentram em uma organização, e isso não é diferente com as mulheres, porém em algumas situações, ao se depararem com uma chance de ascensão na empresa, a não percepção de igualdade nos processos de seleção entre elas e os colegas homens, pode gerar desmotivação e um sentimento de desvalorização.

É nesse sentido que Tadeucci (2009) considera que as pessoas podem apresentar resultados mais gratificantes, ou não em suas metas e objetivos pessoais, ao se sentirem mais motivadas e tiverem condições em seu ambiente de trabalho para atingir suas expectativas. Rocha-Coutinho e Coutinho (2011) assinalam que no ambiente público, ainda há, por parte das mulheres, o enfrentamento de situações que as façam se sentir como intrusas e condições que tendem a situá-las em posições de menor notoriedade dentro das empresas. A autora acrescenta que as empresas dirigidas por homens, a conciliação entre carreira e família torna-se mais difícil.

Sem hora para entrar ou sair, e obrigando seus executivos a trabalhar muitas vezes nos finais de semana e a viajar frequentemente, as empresas dificultam o investimento de seus empregados, sejam eles homens ou mulheres, na constituição e nos cuidados físicos e emocionais envolvidos nas relações familiares. (Rocha-Coutinho; Coutinho, 2011, p. 68)

Em se tratando de relações familiares, em conjunto com o aumento da participação econômica das mulheres, está a alteração na estrutura familiar já que se amplia o número de famílias chefiadas por mulheres (Galeazzi, 2001). São as chamadas famílias monoparentais, chefiadas por pai ou mãe que podem ser solteiros, separados, divorciados ou viúvos e seus filhos 
(Santana, 2014). A vida conjugal tem se modificado no que diz respeito aos papéis de gênero e a configuração familiar tem se desenhado diferente da estrutura de família tradicional.

Com os novos arranjos familiares e as novas configurações nas relações entre homens e mulheres têm surgido novos relacionamentos sexo-afetivos, a frequência de separações dos casais é tal que muitos questionam sobre a evolução da família e as repercussões sobre as novas formas de parentalidade e do significado da maternidade. (Simões e Hashimoto, 2012, p. 5).

Esse tipo de sustentação familiar, onde não há necessariamente um pai, uma mãe e seus filhos, já é uma realidade irrefutável na vida de milhares de brasileiros. Isso sugere que há uma “família em desordem” que, nos termos de Roudinesco (2003), faz-se mister para pensar um distinto formato familiar, não no sentido caótico da concepção de desordem, mas sim do ponto de vista de outra ordem, nem melhor, nem pior, mas diferente.

\section{METODOLOGIA}

Para o desenvolvimento deste estudo, optou-se pela pesquisa qualitativa exploratória (Gil, 2006) onde se buscam respostas às questões do cotidiano das mulheres trabalhadoras e que ocupam cargos de liderança na empresa onde trabalham, gerenciando paralelamente sua vida pessoal.

Para tanto, utilizou-se a entrevista individual como técnica de coleta de dados e que, de acordo com Bauer e Gaskell (2002), trata-se de uma conversação que pode ser agendada para um tempo e lugar conveniente para o entrevistado e que dura normalmente entre uma hora e uma hora e meia e tem como um dos objetivos explorar em profundidade o mundo da vida do indivíduo. Ainda, segundo os autores,

[...] com um entrevistado apenas, podemos seguir detalhes muito mais ricos a respeito de experiências pessoais, decisões e sequências das ações, com perguntas indagadoras dirigidas a motivações, em um contexto de informação detalhada sobre circunstâncias particulares da pessoa. (Bauer e Gaskel, 2002, p. 78).

Para a análise dos dados, utilizou-se a análise de discurso proposta por Bardin (1995) que é uma das ferramentas em meio à análise de conteúdo que permite uma compreensão de cunho semântico - ou relativo ao sentido. Não se trata especificamente de um único método de análise, mas um estilo de interpretação dos dados que implica numa "rejeição da noção realista de que a 
linguagem é simplesmente um meio neutro de refletir, ou descrever o mundo, e uma convicção da importância central do discurso na construção da vida social” (Gill, 2003, p. 244).

Entende-se que o conhecimento é socialmente construído e, portando, exige o desdobramento dos fenômenos nas ações ou práticas ao qual estão ligados (Gill, 2003). Assim, é possível dar ênfase a dados que podem não ser os mais presentes, no sentido quantitativo das amostras, dado que toda informação é importante e pode ser essencial na construção de sentidos ao problema. Pensando especialmente na análise de um discurso associado com um contexto interpretativo, um dos objetivos é "identificar as funções, ou atividades, da fala e dos textos, e explorar como eles são realizados" (Gill, 2003, p. 250). Para tanto, todas as entrevistas serão transcritas e analisadas de acordo com categorias emergentes, de acordo com a qualidade do material coletado.

Para Bardin, a primeira fase da análise dos dados corresponde à codificação que é "efectuada segundo regras precisas - dos dados brutos do texto, transformação esta que, por recorte, agregação e enumeração, permite atingir uma representação do conteúdo, ou da sua expressão". (Bardin, 1995, p. 129). A partir desta codificação, são relacionados aos dados extraídos do texto unidades de sentido, que serão organizadas segundo categorias que compreendem semelhantes qualidades de sentido. O que ilustra a categoria, por sua vez, é a unidade de registro que e quando “executam-se certos recortes a nível semântico, o 'tema', por exemplo, enquanto que outros são feitos a um nível aparentemente linguístico, como por exemplo a 'palavra' ou a 'frase" (Bardin, 1995, p. 130).

Participaram seis mulheres que ocupam cargos de gestão nos setores de Gerência de Relações com o Mercado, Gerência da Divisão Administrativo-Financeira, Gestão de Engenharia, Assessoria de Gestão Estratégica, Gestão de Controladoria e Assessoria Jurídica, escolhidas de forma aleatória. As entrevistadas, cujos nomes foram alterados por motivos de sigilo, trabalham em uma empresa parafiscal de direito privado, fundada em 1946, presente em todos os estados da Federação e no Distrito Federal, tendo como função a prestação de serviço social aos trabalhadores e empresas do segmento industrial. Na unidade do estado do Rio Grande do Sul trabalham 1.949 funcionários, sendo 1.311 mulheres. Em relação ao grau de instrução, 1.071 funcionários possuem nível superior: 754 mulheres e 317 homens, sendo que, 20 delas são gestoras.

As entrevistas foram autorizadas segundo termo de consentimento livre e esclarecido e abordaram os temas: planejamento de carreira; trabalho e família; estilo de liderança. Tais temas foram postulados, a priori, como categorias na análise das conversações, sendo as informações de cada eixo temático da análise desenvolvidos após a codificação dos dados levantados.

Revista de Gestão e Secretariado - GeSec, São Paulo, v.6, n. 2, p 88-110, maio./agosto. 2015. 
Por fim, foi investigada a percepção do Diretor Superintendente da empresa em relação à diferença entre a liderança masculina e feminina como vantagem competitiva na organização, e analisada na categoria: Características da liderança de gênero do ponto de vista do líder homem.

\section{ANÁLISE DOS DADOS}

O discurso comum de todas as entrevistadas referente ao plano de carreira, primeira categoria de análise a ser descrita, foi enfatizado por narrativas acerca dos esforços e do comprometimento pessoal, já que elas destacam suas conquistas sem favorecimentos no processo de ascensão hierárquica. Isso nos leva a inferir a necessidade das líderes de mostrarem-se efetivamente capazes de galgar seus próprios postos de trabalho, haja vista eu muitas das identificações feitas às mulheres em cargos de liderança, de um ponto de vista machista, sugerem eventuais favorecimentos da mulher em ascensão no mercado de trabalho, já que ela não seria capaz de alcançar bons cargos a próprio mérito. No entanto, ao contrário desta falácia do senso comum, trajetórias destas líderes foram de desenvolvimento e aperfeiçoamento, sendo que elas relatam terem passado por todos os cargos na empresa até chegarem à função que ocupam hoje, que é a gestão de equipes.

Também foi apontado como dado de pesquisa a supervalorização dos espaços de estudos, corroborando com as informações já citadas neste trabalho que constam a expansão da escolaridade por parte das mulheres. Dentre as entrevistadas, por exemplo, todas possuem no mínimo uma titulação de especialista, até mesmo por ser condição para o exercício do cargo. Elas relatam que começaram a trabalhar muito cedo e sempre procuraram conciliar o turno de trabalho com os estudos, adquirindo conhecimentos e vivenciando experiências já em suas áreas de formação.

\footnotetext{
Minha carreira foi planejada e pensada. Todos os cursos e as seis pós-graduações e especializações que fiz, sempre foram para trabalhar na área de relacionamento com o mercado e sempre uma especialização complementando a outra, porque nem só a faculdade e nem só teu trabalho te abrem visão para as coisas. Foi bem trabalhoso. (Rosa)
}

Mostraram-se, assim, preocupadas na questão do autoconhecimento para o desenvolvimento da liderança. Duas delas passaram pelo processo de trainee e relatam que foi um processo longo, árduo e de dedicação exclusiva.

Me inscrevi para o primeiro programa de trainee e não passei, foi uma decepção. Daí quando não passei, eu queria me entender melhor. Porque não passei? Quais são os aspectos ou o que eu não tenho e que a empresa está precisando? (Acácia).

Revista de Gestão e Secretariado - GeSec, São Paulo, v.6, n. 2, p 88-110, maio./agosto. 2015. 
Embora a capacidade e o autodesenvolvimento estejam diretamente relacionados à realização profissional das entrevistadas, a segunda categoria analítica refere-se à dificuldade na conciliação entre o trabalho e a família, que foi considerada uma forma de superação no alcance dos objetivos planejados. Além disso, uma das líderes menciona que teve de abrir mão de tudo, família, casa, marido, em função da carreira, queria se "experimentar", para ver o que era gestão. Relata que teve de trabalhar muito "o não sofrer" nas decisões tomadas, mas a vontade de vencer e o sentimento de dever cumprido prevaleceram. Isso mostra que há perspectivas, ainda a serem melhor exploradas em pesquisa, que sugerem a ampliação desta figura da mulher em posição gerencial que abre mão propositalmente do foco em uma perspectiva familiar, como a maternidade, por exemplo, para doar-se ao trabalho, o que é uma mudança significativa à imagem historicamente construída da mulher.

Contudo, as que não fizerem esta opção pela dedicação exclusiva ao trabalho ainda terão de enfrentar uma série de desafios na busca por esta conciliação. Para uma das gestoras, a grande dificuldade e momento de maior sofrimento durante a trajetória profissional foi deixar a filha na creche com apenas quatro meses de idade para assumir um cargo de gerência. Apesar de garantirem que a maternidade também traz motivação para seguir perseguindo os objetivos de trabalho, esta mãe afirma que não está autorizada a ficar doente, por exemplo, pois precisa trabalhar e ter condições de dar uma vida boa para a filha. Assim, é perceptível que não há ainda nos espaços de trabalho um ambiente que possibilite a interlocução entre a maternidade e a carreira. O que há são cargos masculinizados, pensados a partir da lógica do homem, cuja tradição desde sempre autorizou o distanciamento da família, uma vez que a mulher era quem cuidava do lar. Contudo, mesmo com os avanços adquiridos no que diz respeito às mulheres e o mercado de trabalho, ainda não existem boas perspectivas em relação à flexibilização das mães nos seus espaços de trabalho. O que existe é o medo recorrente que eventuais ausências possam gerar uma demissão indesejada, o que faz com que a mulher torne, por vezes, inalterada a sua rotina de trabalho, mesmo com uma criança recémnascida para criar.

Diante do possível, segundo as entrevistadas que são mães, a chegada de um filho fez com que algumas de suas prioridades mudassem, já que há relatos delas quanto à fixação de horários de trabalho evitando horas extras, por exemplo, a fim de dedicar mais tempo de seu dia à família. Porém, um dos relatos afirma que:

Tem o sacrifício pessoal da convivência com o filho. É o padrão da mulher que está no mercado de trabalho. Trabalhar até muito tarde. E isso é complicado. Teve uma vez que eu

Revista de Gestão e Secretariado - GeSec, São Paulo, v.6, n. 2, p 88-110, maio./agosto. 2015. 
estava envolvida em uma pesquisa, tinha que viajar para o exterior, trabalhava até tarde fazendo pesquisa, lembro do meu filho pequeno... uma vez fui botar ele na cama e ele me disse assim: "mãe, tu nunca tá comigo, mas não tem problema, eu tenho o meu pai." (Dália).

Esse episódio sugere que há a inferência da figura paterna na criação do filho e mostra uma reestruturação familiar no sentido de uma possível mudança na figura materna, tornando-a mais presente em vista da parcial ausência da mãe. Por outro lado, contudo, as duas gestoras que optaram por não ter filhos, assinalaram que foi um facilitador na trajetória de carreira, tinham a agenda mais livre, podiam viajar, ficar até mais tarde no trabalho e suprem o lado maternal com a convivência com os sobrinhos. A gestora que ainda não tem filhos, diz que está em processo de planejamento e organização para que o desejo de ser mãe se concretize em breve.

As entrevistadas foram incentivadas a comentar sobre a terceira e última categoria, que trata dos estilos de liderança, destacam que as suas motivações, tanto no trabalho como em suas vidas pessoais, remetem ao propósito do trabalho a ser executado, o resultado do trabalho em equipe e o valor que o trabalho benfeito traz às pessoas. "O que mais me motiva aqui dentro é saber que o movimento que a gente está fazendo está no caminho certo, pelos retornos que a gente recebe" (Acácia). Ou seja, elas o fato de verem as coisas sendo executadas e implementadas, isso tanto no profissional quanto no pessoal, apresentando-se como verdadeiras agentes independentes das suas vidas e decisões. Os desafios as impulsionam e, assim, mostram-se um pouco inquietas e ousadas no sentido de não conseguirem ou não gostarem de fazer sempre as mesmas coisas. "Me incomoda essa coisa de eu ser refém do medo. Se não sei algo, vou lá, encaro, faço”. (Angélica). São estimuladas pelo simples fato de estarem trabalhando com o que gostam e almejaram. "É engraçado eu dizer, mas eu amo levantar de manhã e vir pra cá, desde sempre, desde quando eu era assistente até agora na gestão". (Hortênsia).

Esses relatos reafirmam a importância do trabalho como formador de identidade e, porque não, como divinizador do ser humano. Esta atividade, que embora seja motivo central da fadiga humana, também é seu eixo estruturante, o que atribui à mulher uma outra função política e social, omitida em tempos onde o trabalho feminino circunscrevia o limite do privado. Além disso, elas acreditam na capacidade de transformação: "eu quero ver uma empresa menos conservadora, diferente, eu quero poder influenciar isso". (Dália). Isso sugere a ousadia feminina tentando romper com um padrão de liderança machista, para dar o exemplo de que mulher pode mudar alguns padrões e conceitos socialmente construídos.

Revista de Gestão e Secretariado - GeSec, São Paulo, v.6, n. 2, p 88-110, maio./agosto. 2015. 
No modo como gerenciam suas equipes, houve unanimidade nos depoimentos: elas enfatizam a forma participativa e democrática de gestão a fim de manter a equipe sinérgica, trazendo bons resultados à organização. Contam que lideram a equipe da mesma forma como gostariam de ser geridas pelos seus superiores, dando mais liberdade na condução do trabalho, maior espaço de participação, oferecendo oportunidade às pessoas para que se desenvolvam pessoalmente, orientando-as do caminho a ser seguido. "Eu tenho um legado para deixar, e esse legado me instiga o tempo inteiro, porque um legado não se faz sozinha, eu sou o resultado das minhas equipes, o resultado do meu time.” (Acácia).

Para elas, o trabalho em equipe é fundamental no ambiente corporativo e, por isso, fazem reuniões com frequência, pois acreditam que o compartilhamento de informações é muito importante para o andamento dos processos. "Tento ser o mais transparente e justa possível" (Hortênsia).

Por outro lado, há depoimentos em que o gerenciamento situacional prevalece em determinados momentos, precisando impor o rigor na condução do trabalho. Se elas percebem que as coisas estão passando dos limites, há a intervenção.

[...] Então é uma mescla, uma hora tu tem que ser ouvinte, uma hora tu tem que ser a chefe deles, uma hora tu tem que ser aquela pessoa que vai ser professora. (Acácia).

Eu paro, ouço e estou sabendo dosar o emocional e o racional na condução do trabalho. (Angélica).

As entrevistadas se mostram preocupadas com o perfil de liderança que vem sendo aplicado por elas nas empresas, afirmando que é preciso buscar rever permanentemente suas questões para com a equipe, o que sugere não uma fórmula de liderança já definida, mas sim estratégias transitórias e situacionais, que independem na prática de diferenças de gênero, mas das especificidades gerenciais.

Contudo, fala-se muito da valorização da "liderança feminina" nas organizações no que se refere às características essenciais e naturais da mulher. Esse é um aspecto levantado no discurso do Diretor Superintendente da empresa, que considera a líder mulher um ponto positivo e de grande vantagem em relação à "liderança masculina". Menciona que, pela natureza de ser, as mulheres entendem das necessidades das pessoas, possuem algumas qualidades intrínsecas. Na visão dele, o homem tende a pensar de uma forma mais dura, no sentido de que às vezes ele não olha a pessoa Revista de Gestão e Secretariado - GeSec, São Paulo, v.6, n. 2, p 88-110, maio./agosto. 2015. 
em si, ele olha os processos, os custos, a unidade. A mulher é mais atenta às condições da pessoa no seu meio, na sua família, e que isso facilitaria também em relação ao cliente e ao público interno, uma forma mais humanizada de ser. Considera o masculino mais cartesiano, sendo que a mulher traz à tona uma série de questões que o homem não pensaria.

A mulher tem um olhar sistêmico, um pertence, a mulher está se preparando melhor. Ela conseguiu e isso é uma tendência geral no mundo. (Diretor Superintendente).

Por mais que as mulheres venham ocupando cargos de liderança de forma crescente, pelo menos no que diz respeito à empresa pesquisada, a proposta deste estudo não é produzir diferenças de gênero entre os líderes, mesmo que o discurso esteja enfeitado em prol da valorização feminina. Ou contrário, advoga-se pela igualdade de gênero nos espaços de trabalho, onde as pessoas possam ser definidas pelas individualidades das suas ações e não por generalizações atribuídas ao sexo.

Ainda, em seu discurso, o Diretor Superintendente chama a atenção para um aspecto: a masculinização da mulher quando chega ao alto escalão da empresa. Mostra-se preocupado, nesse sentido, em relação aos atributos femininos que fizeram diferença em sua trajetória, atributos que levam ao equilíbrio. E esse equilíbrio desaparece quando a mulher assume características e comportamentos masculinos, achando que serão mais respeitadas e reconhecidas, começando a exercer uma liderança mais "ditadora", destaca ele, tão duronas quanto os colegas do sexo masculino.

E finaliza ponderando que:

[...] a grande questão da liderança é tu ter a diversidade, pra que tu possa fazer o crescimento acontecer e isso é que vai fazer a grande diferença, fazer as empresas crescerem, enfim... abordando outras questões que não se tinha antes. A riqueza está nisso. (Diretor Superintendente).

Esta fala vem ratificar uma das premissas deste trabalho, de que a liderança feminina não só é tão eficaz quanto à forma de liderar do homem, como ainda, é uma importante política organizacional ainda a ser trabalhada e pensada, no sentido de oportunizar que mais mulheres ganhem a confiança da empresa para poderem assumir cargos de gestão sem sofrerem com o preconceito das desigualdades de gênero.

A forma como administram os conflitos, sendo exigentes e fortes quando necessário, sugere maturidade no processo de gerenciamento das entrevistadas. Em contrapartida, mostram-se 
sensíveis, atenciosas e flexíveis, apresentando uma visão mais grandiosa do negócio, qualidades e características apontadas na declaração do Diretor Superintendente da empresa, consistindo em um diferencial na administração das organizações, atributos esses, que os homens, via de regra, não manifestam, referindo-se a eles como mais duros e objetivos, preocupados com os resultados e números. Por outro lado, e ainda na visão do Diretor, não deveria haver a descaracterização do feminino por parte das líderes, já que estas deve manter os atributos e peculiaridades que as diferenciam no processo de ascensão de carreira. Assim, o diretor da organização considera em seu discurso que essa diversidade identitária dos líder traz benefícios às corporações ao complementar o quadro funcional justamente nas diferenças singulares. Do ponto de vista deste estudo, mesmo que as diferenças de gênero historicamente constituídas por vezes efetivamente existem, o que distingue as pessoas são atributos individuais que não podem ser associados ao sexo de cada sujeito.

\section{CONSIDERAÇÕES FINAIS}

Apresentadas as diversas situações enfrentadas pelas mulheres que galgaram melhores posições dentro da empresa, superando dificuldades e fazendo escolhas para poder desenvolver uma carreira forte e consolidada, observa-se que elas valorizam muito suas profissões, fazendo o que gostam, desafiando-se e sentindo-se motivadas no exercício de suas funções apesar de serem constantemente postas à prova nas suas atividades pelo fato de serem mulheres.

Ainda que tenham cargos de grande responsabilidade e condição de líderes influentes na empresa, as mulheres manifestam preocupação em equilibrar o trabalho com a família e sua vida privada; determinadas decisões trouxeram sofrimento e culpa por não darem a devida atenção como gostariam - sentimento que não acontece na mesma proporção nos homens. Isso mostra que a mulher, além de ser considerada, grosso modo, incapaz para desenvolver uma atividade majoritariamente masculina, ainda enfrenta a dupla jornada de trabalho ao responsabilizar-se pelas tarefas de casa e dos filhos, quando houver. Identifica-se, ainda, a necessidade da mulher em mostrar a capacidade profissional para comprovar a conquista do cargo, que ocorreu por mérito e esforço próprios e não por outras questões como a de favorecimento, por exemplo.

Observa-se, também, no discurso delas, a consideração e o modo como tratam suas equipes, por meio do compartilhamento do conhecimento e informações e na liberdade na condução dos processos, um forte motivo que mantém a equipe unida, confiante e motivada, trazendo resultados satisfatórios aos objetivos traçados. Tais aspectos mostram que não há qualquer empecilho atribuído ao gênero quanto à condução das atividades de gestão e liderança.

Revista de Gestão e Secretariado - GeSec, São Paulo, v.6, n. 2, p 88-110, maio./agosto. 2015. 
Infere-se que a mulher, ao chegar na gestão, elabora a sua identidade, no que diz respeito as qualidades e competências adquiridas, de tal forma que, embora se distinga das demais líderes homens ou mulheres, podem ser relevantes para a organização já que as particularidades de cada um são passíveis de serem apropriadas dentre as divisões de tarefas da organização onde as diferenças passem a ser construtivas e não problemáticas.

Conforme foi destacado no decorrer deste estudo, ocorre a crescente participação das mulheres em postos de liderança, porém, como apontado em pesquisas recentes, a desigualdade ainda se mantém, por exemplo, em se tratando de salários percebidos por mulheres e homens no mercado de trabalho - o que justifica ainda estar aberto o aprofundamento sobre o tema. Não obstante, elas têm trilhado uma carreira um pouco pioneira e até solitária, da sua forma, por ser uma geração que vivencia a liderança quando ela ainda é praticamente uma novidade para a realidade feminina, ou seja, ser líder e mulher ainda é pauta para notícias de capa de revistas e matérias de telejornais, efetivamente tido como fato raro. De todo modo, acredita-se que a sociedade e as organizações têm muito a ganhar no sentido de rever certas suposições masculinizadas, não só pelo ganho estratégico de contar com profissionais competentes, mas também por se valer de uma gestão mais humana, associada à participação e ao engajamento das pessoas.

A ideia de que às mulheres só cabe o cuidado com o lar, marido e os filhos, mostra-se um discurso absolutamente ultrapassado em relação ao entendimento das identidade de gênero. Hoje é perceptível a profissionalização das mulheres que, por sua vez, todavia não abandonaram as atividades domésticas. Assim, aspectos da luta pela igualdade no mercado de trabalho transcendem a vida privada, no que diz respeito à constante e dificultosa tarefa de igualar as atividades da casa para além de um ponto de vista machista.

No que tangem perspectivas de estudos futuros, considera-se apropriado pensar a inserção de grupos homossexuais, por exemplo, no ambiente empresarial. As questões de desigualdade de gênero abarcam uma discussão muito mais ampla do que o recorte deste estudo, que optou por uma perspectiva dual de gênero e não levou em conta aspectos de classe, raça, etnia e opção sexual. Ou seja, estas demais premissas empíricas que dialogam diretamente com a identidade de gênero no mercado de trabalho apresenta-se como uma das demandas da contemporaneidade. Assim como a condição da mulher nos espaços de liderança tem se expandido ao longo dos anos, embora não distante ainda dos violentos abusos provocados outrora pelo imperativo dominante masculino, considera-se, de modo otimista, que em um futuro breve se possa ampliar ainda mais as discussões e ações acerca do tema, especialmente cunhados aos cargos de destaque empresarial. 


\section{REFERÊNCIAS}

Araújo, L. C. G; Carmo, M. S. \& Matesco, K. (2013). Ações estratégicas: desafios e caminhos para a gestão contemporânea. São Paulo: Atlas.

Bardin, Laurence (1995). Análise de conteúdo. Porto: Edições 70.

Bauer, M. \& Gaskell, G. (2002). Pesquisa qualitativa: com texto, imagem e som. Petrópolis: Vozes.

Bruschini, C. (2000). Gênero e trabalho no Brasil: novas conquistas ou persistência da discriminação: In: Baltar da Rocha, M. I (org.) Trabalho e gênero: mudanças, permanências e desafios. São Paulo: Editora 34.

Bruschini, C. (2007). Trabalho e gênero no Brasil nos últimos dez anos. Cadernos de Pesquisa, São Paulo, vol. 37, n.132, pp.537-572, set./dez.

Bruschini, C. \& Puppin, A. B. (2004). O trabalho de mulheres executivas no Brasil no final do século XX. Cadernos de Pesquisa, São Paulo, vol. 34, n.121, pp. 105-138, jan./abr.

Dutra, J. S. (2002). A gestão de carreira. In: Fleury, M. T. L. (org.). As pessoas na organização. São Paulo: Gente.

Fontenele-Mourão, T. M. (2006). Mulheres no topo de carreira: flexibilidade e persistência. Brasília, DF: Secretaria de Política para as Mulheres.

Galeazzi, I. (2001). Mulheres trabalhadoras: a chefia da família e os condicionantes de gênero. Mulher e Trabalho. Porto Alegre: FEE; FGTAS/Sine-RS; Dieese; Seade-SP; FAT, vol. 1, pp. 61-68.

Gil, A. C. (2006). Métodos e técnicas de pesquisa social. (5a ed.). São Paulo: Atlas.

Gill, R. (2003). Análise de Discurso. In: Bauer, M; Gaskell, G. Pesquisa qualitativa: com texto, imagem e som. Petrópolis: Vozes.

Hofmeister, D. L. F. (2009). Planejamento e desenvolvimento de carreira. Curitiba: Iesde Brasil.

Hunter, J. C. (2006). Como se tornar um líder servidor: os princípios de liderança de o monge e o executivo. Rio de Janeiro: Sextante.

Instituto Brasileiro de Geografia e Estatística - IBGE (2012). Pesquisa Nacional por Amostra de Domicílio - PNAD. Síntese de indicadores sociais: uma análise das condições de vida da população brasileira. Rio de Janeiro.

Kanan, L. A. (2010). Poder e liderança de mulheres nas organizações de trabalho. Organização $e$ sociedade, Salvador, vol. 17, n. 53, pp 243-257, abr./jun.

Menda, P. B. (2004). Análise da dicotomia sofrimento e prazer na função gerencial feminina. Dissertação de Mestrado do Programa de Pós-graduação em Administração, UFRGS, Porto Alegre, RS, Brasil.

Revista de Gestão e Secretariado - GeSec, São Paulo, v.6, n. 2, p 88-110, maio./agosto. 2015. 
Nicholson, Linda (2000). Interpretando o gênero. Revista Estudios Feministas, CFH/CCE/UFSC, vol. 8, n. 2, Brasil, Santa Catarina, pp. 8-41.

Oliveira, D. P. R.(2009). Plano de Carreira: foco no indivíduo. São Paulo: Atlas.

Piscitelli, Adriana (2008). Interseccionalidades, categorias de articulação e experiências de migrantes brasileiras. Sociedade e Cultura, vol. 11, n. 2, jul.-dez. pp. 263 a 274. Recuperado de http://www.revistas.ufg.br/index.php/fchf/article/view/5247/4295.

Robbins, S. P.; Decenzo D. A. \& Wolter, R. M. (2013). Fundamentos de gestão de pessoas. São Paulo: Saraiva.

Rocha-Coutinho, M. L. \& Coutinho, R. R. (2011). Mulheres brasileiras em posições de liderança: Novas perspectivas para antigos desafios. Economia Global e Gestão, Lisboa, vol. 16, n. 1 , abr.

Roudinesco, E. (2003). A Família em Desordem. Rio de janeiro: Jorge Zahar.

Santana, E. L. F. F. (2014). Família monoparental feminina: Fenômeno da contemporaneidade? POLÊM!CA: Laboratório de Estudos Contemporâneos. Universidade do Estado do Rio de Janeiro, v. 13, n. 2, p. 1225-1236.

Santos, J. C. S. (2014). Masculinidades, feminilidades e androginia: uma análise interpretativa sobre a construção social de gêneros e suas implicações para o exercício da liderança no Poder Judiciário de Rondônia. 2013. Tese (Doutorado em Administração), Programa de Pós-graduação em Administração, Universidade Federal do Rio Grande do Sul, Porto Alegre.

Silva, M. A. (2000). Todo poder às mulheres: esperança de equilíbrio para o mundo. São Paulo: Best Seller.

Simões, F. I. W. \& Hashimoto, F. (2012). Mulher, mercado de trabalho e as configurações familiares do século XX. Revista Vozes dos Vales: Publicações Acadêmicas: Universidade Federal dos Vales dos Jequitinhonha e Mucuri, Minas Gerais, vol. 1, n. 2, Out.

Tadeucci, M. R. (2009). Motivação e liderança. Curitiba: Iesde Brasil S.A., 2009. 